\title{
Fermilab
}

Fermilab-TM-2674-AD-APC

\section{Radiation Shielding Calculations for E1039 Seaquest Experiment}

\author{
Carol Johnstone, Igor Rakhno
}

April 11, 2018

\section{Introduction and Background}

The E1039 Seaquest experiment is designed to study results of interactions of the $120 \mathrm{GeV}$ proton beam, delivered from Main Injector, with transversely polarized hydrogen target in the form of liquid ammonia (NH3). The E1039 experiment is re-using the Neutrino-Muon beamline, spectrometer magnet (FMAG), KMAG, and other hardware from its predecessor-the E906 experiment. Only the central 2 Tesla magnetic field was modeled in the FMAG magnet which also serves also as a beam absorber. Various updates were performed to the beamline and shielding around the magnet compared to E906 including relocation of the target 3 meters upstream of the front face of FMAG. Further, several updates were performed on the MARS15 model developed previously [1-2] in order to better describe important surrounding areas, in particular the counting room. Several optimization iterations of the shielding design were done and only the final configuration is discussed in this document. The model includes realistically stacked concrete shielding blocks along with airgaps required for piping, ductwork and detectors. The main features of the shielding update can be summarized as follows: (i) additional concrete shielding was added above the magnet to degrade the energy of neutrons to thermal levels; (ii) a new target alcove with the target cryostat inside. These updates are intended to provide increased protection for both normal operation and accident conditions upstream of the target. The Figures 1 thru 3 below describe the MARS15 model in detail as well as an excerpt of the 3D CAD model design which was used to build the MARS15 model.

\section{Simulation}

\section{MARS Model and Beam Parameters}

For these calculations, a proton beam intensity of $1.67 \times 10^{11}$ proton/second was again assumed. The low energy neutrons were modeled down to $10^{-3} \mathrm{eV}$. A Gaussian beam distribution with $\sigma_{\mathrm{x}}=$ $\sigma_{\mathrm{y}}=3.5 \mathrm{~mm}$ was used. The Monte Carlo modeling started immediately upsteram of the steel collimator placed upstream of the target cryostat and shown in Figure 1. The target itself was modeled as a cylinder located inside the target cryostat and with its axis coinciding with the Zaxis.

For points of interest, A thru C, were identified previously [1] by Neutrino Muon Shielding Assessment, and these points (areas) are re-used for this assessment: (i) inside NM4 at upstream 
end of concrete cave, beam left; (ii) inside NM4 looking North or downstream, parking lot; (iii) inside NM4 adjacent to NM4 gas shed; (iv) inside NM4 roof above the upstream end of the concrete cave. A detailed description of these areas is provided in [1]. In addition, the downstream part of the counting room is also considered for occupancy levels.

In order to determine prompt dose in the counting room, a separate skyshine calculation has been performed.
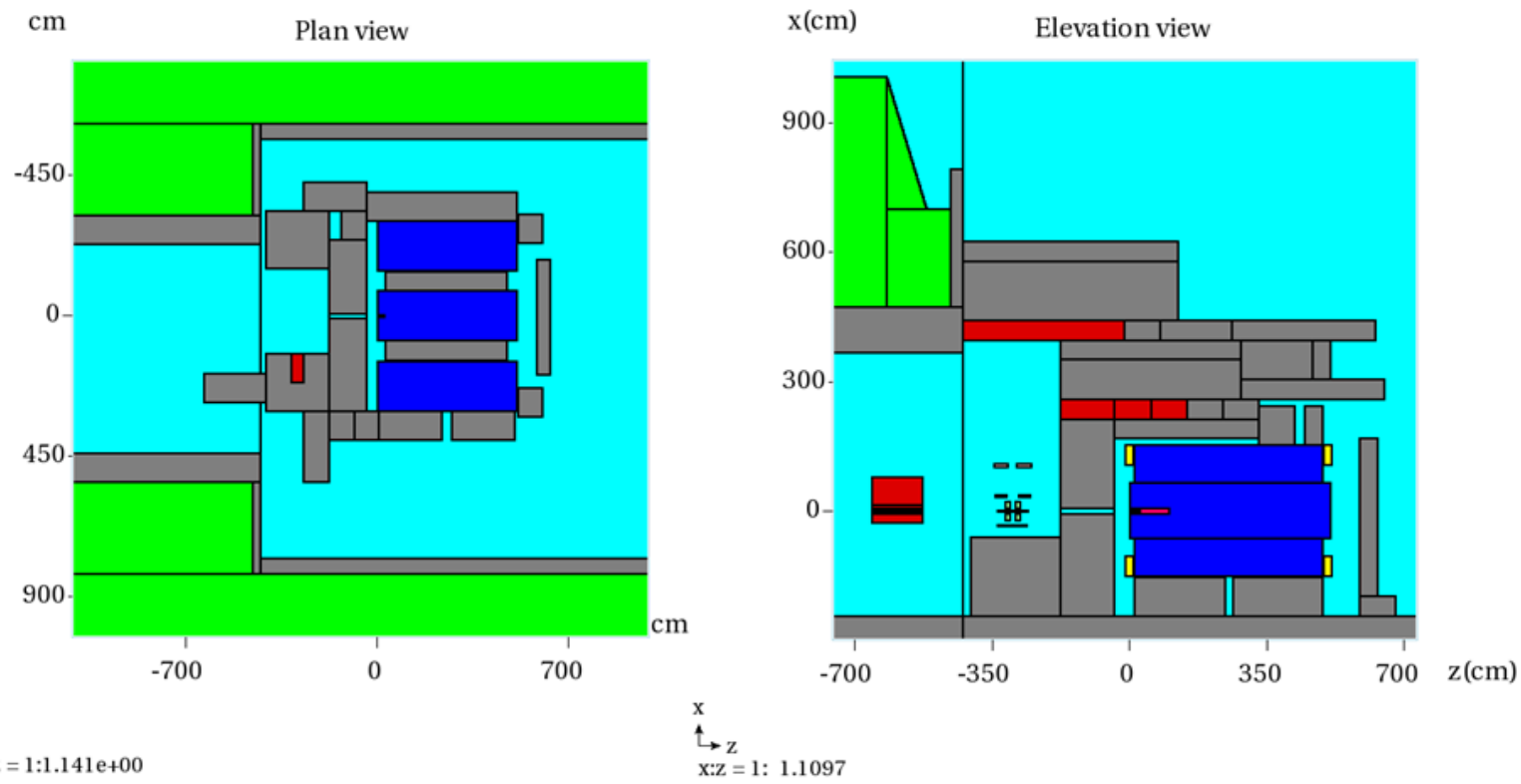

$\vec{\gamma}_{\mathrm{y}}^{\mathrm{z}: \mathrm{z}=1: 1.141 \mathrm{e}+00}$

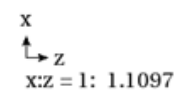

Figure 1. MARS15 model of the FMAG magnet and shielding around it in NM4 and upstream. The color code is the following: light blue, grey, green, dark blue and red correspond to air, concrete, soil, iron and steel, respectively. The small (thin) components of the target cryostat and the collimator may look distorted due to limited resolution of the figures. 


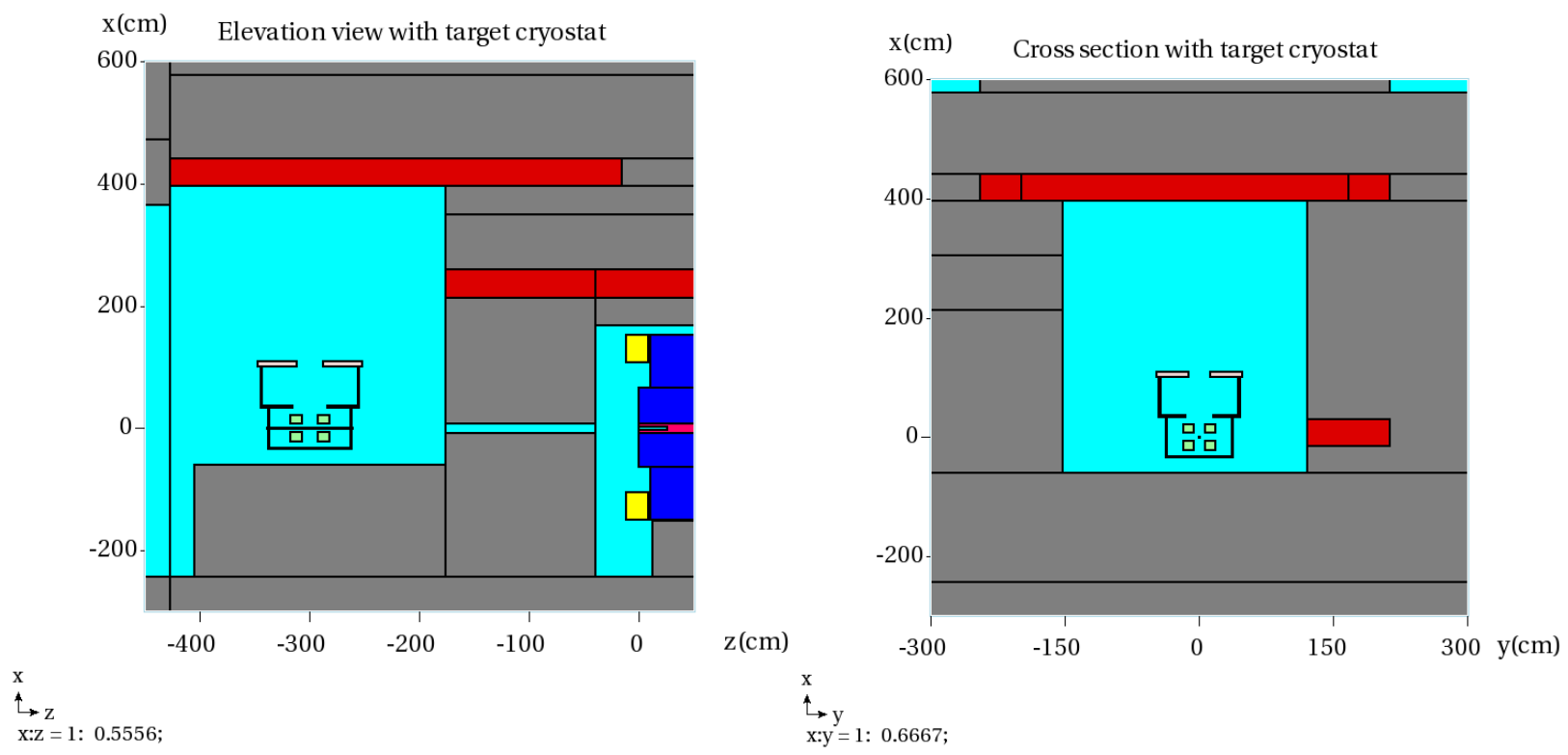

Figure 2. Slices of the MARS15 model with the target alcove and target cryostat inside it: in elevation view (left) and in cross section (right) along beam centerline and target center, respectively.

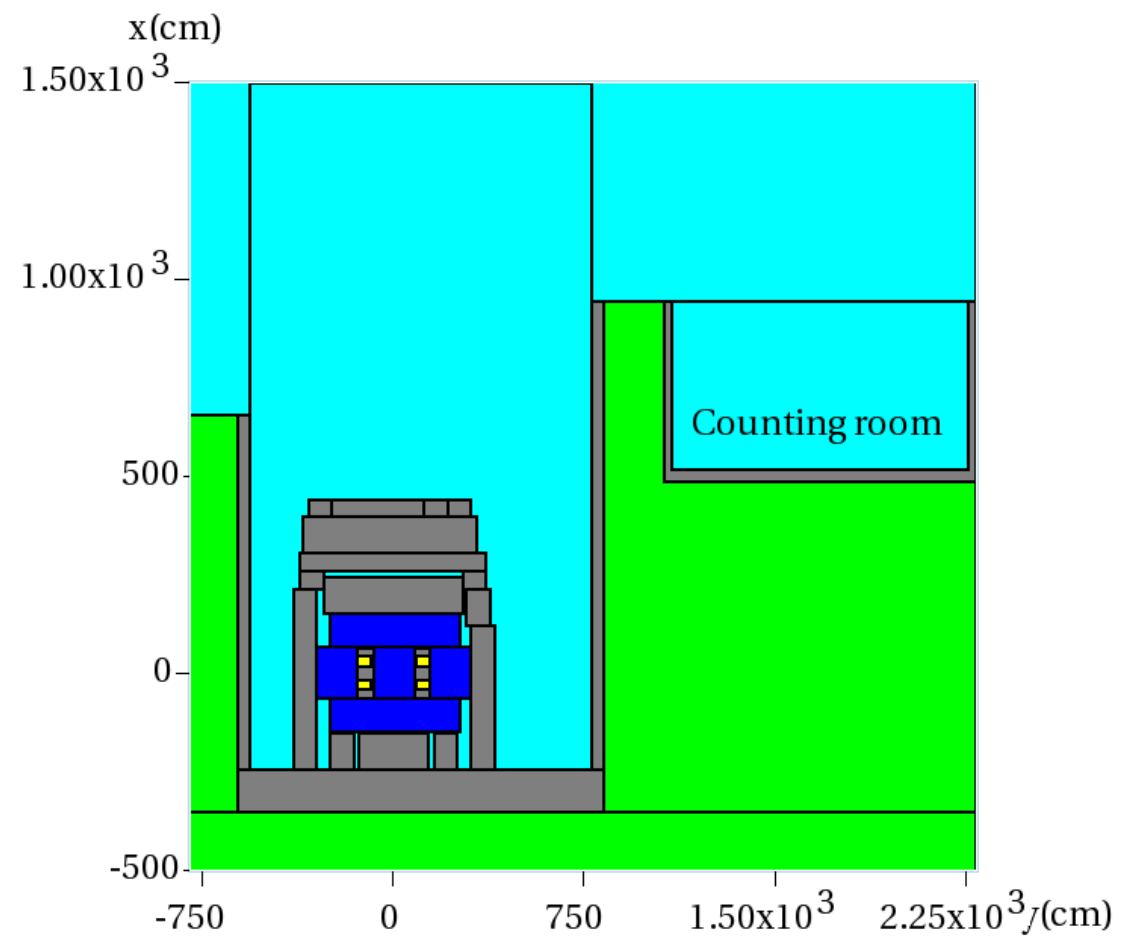




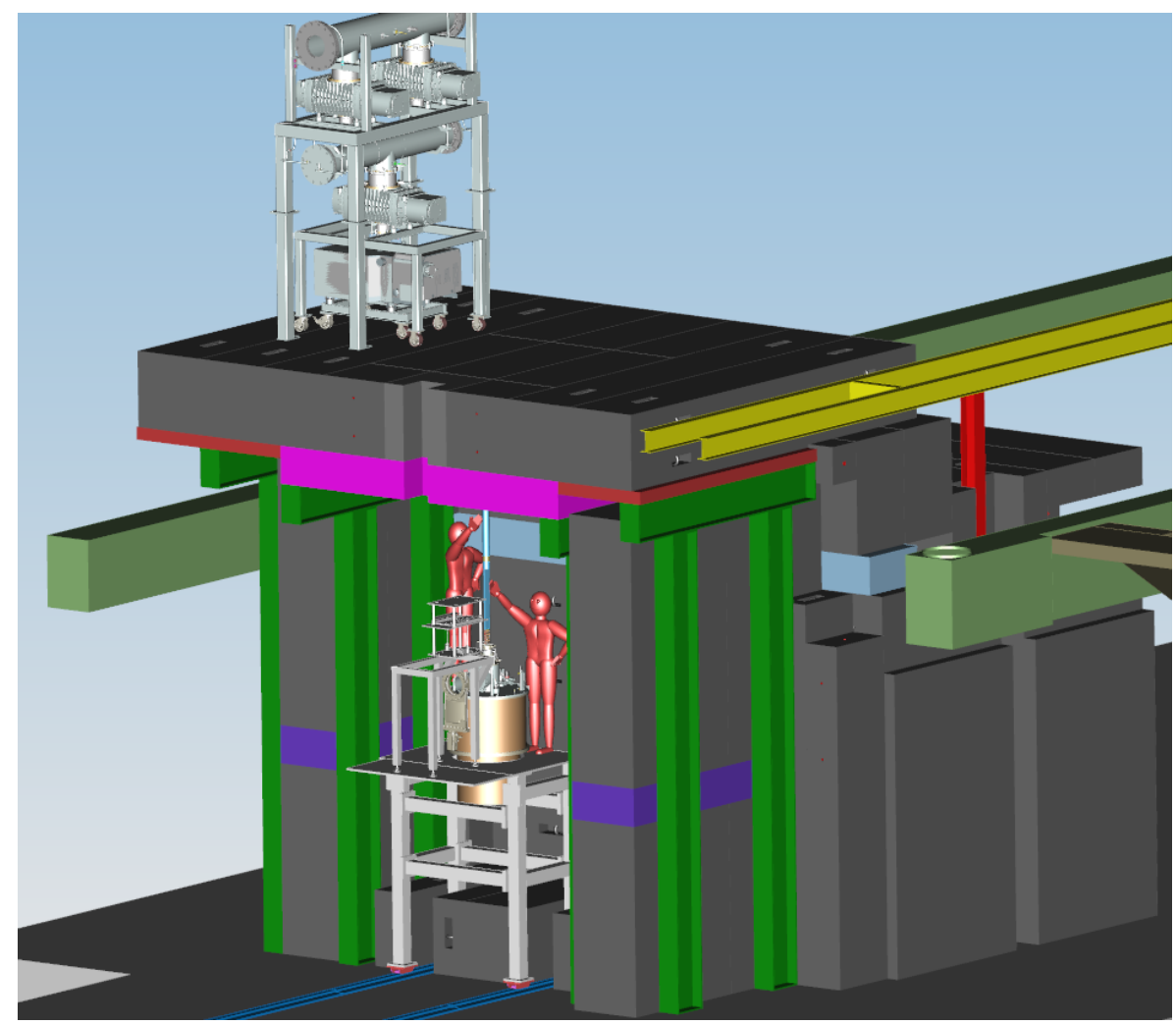

Figure 3. A cross section view of the MARS15 model that shows the counting room; in the model, the room extends longitudinally from $Z=150$ to $1400 \mathrm{~cm}$ (top). The 3D CAD model used to build the MARS15 model (bottom) shows the details of the concrete shielding blocks around the magnet and the target alcove.

The calculated star density and prompt dose distributions around NM4 are shown in Figures 4 and 5 , respectively. The prompt dose distributions in the counting room are shown in Figure 6. The residual dose distributions around the magnet are given in Figure 7. More detailed data on residual dose distributions around the target alcove are shown in Table 1 and Figure 8. 


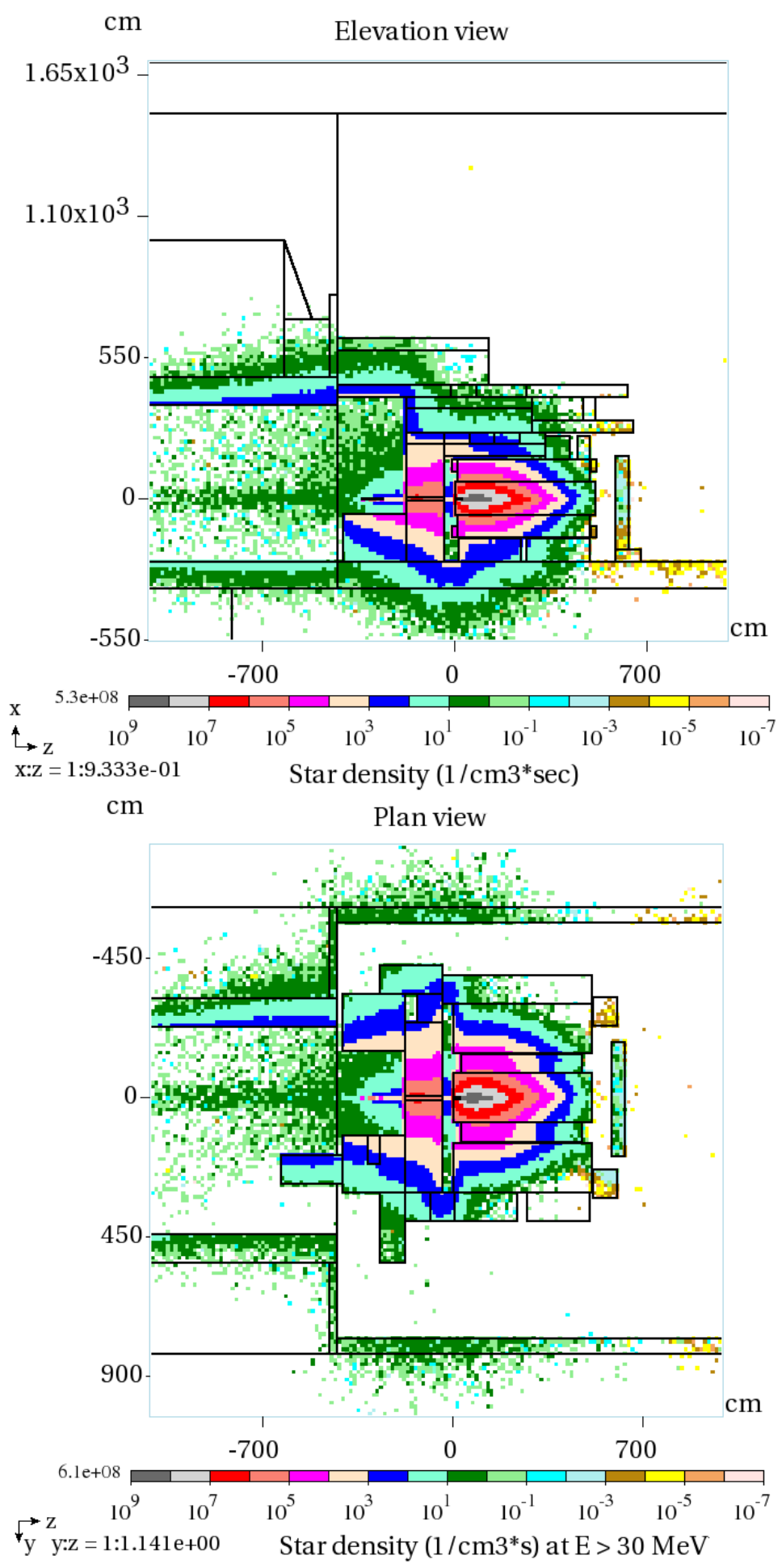

Figure 4 . The calculated star density distributions around NM4. 


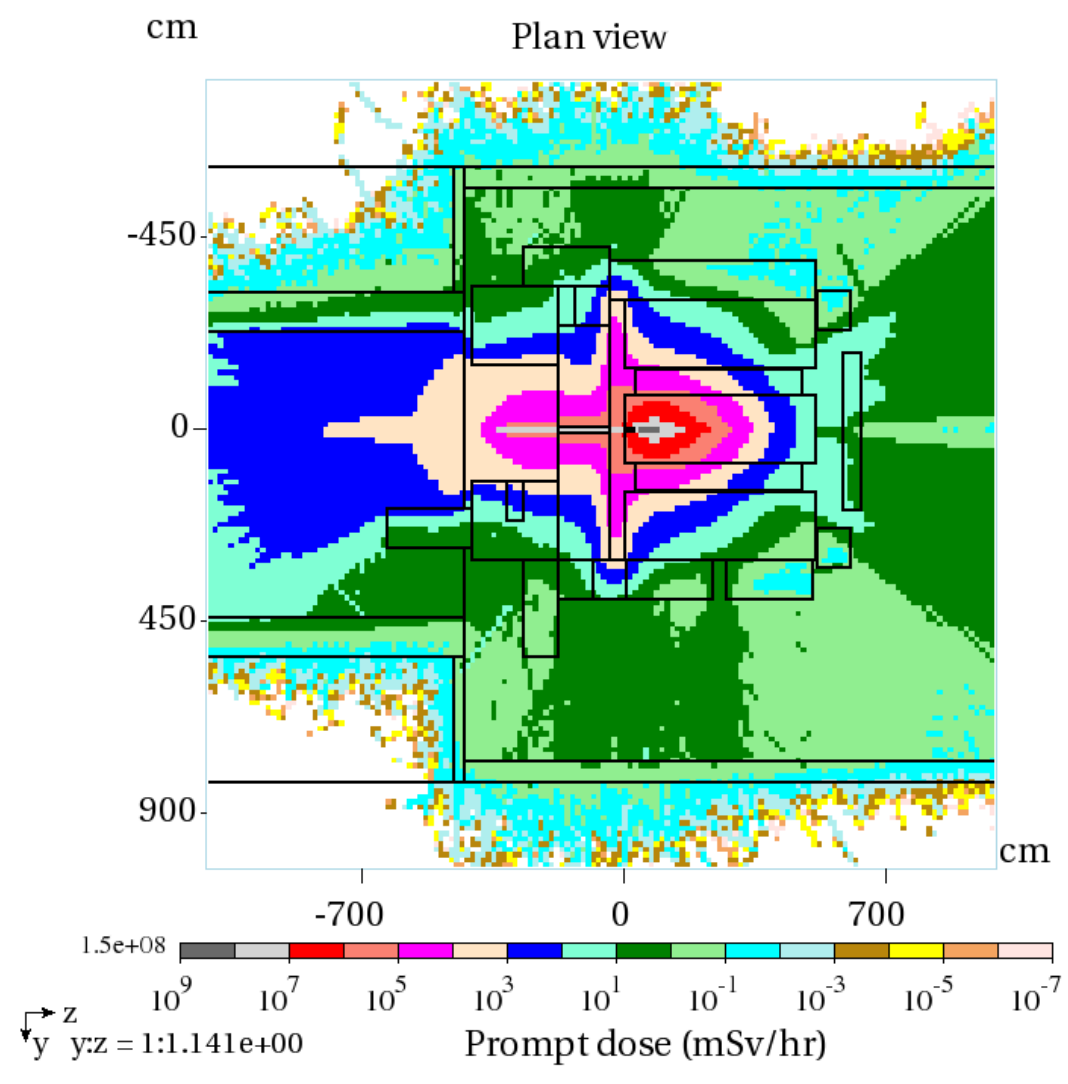

$\mathrm{cm}$

Elevation view

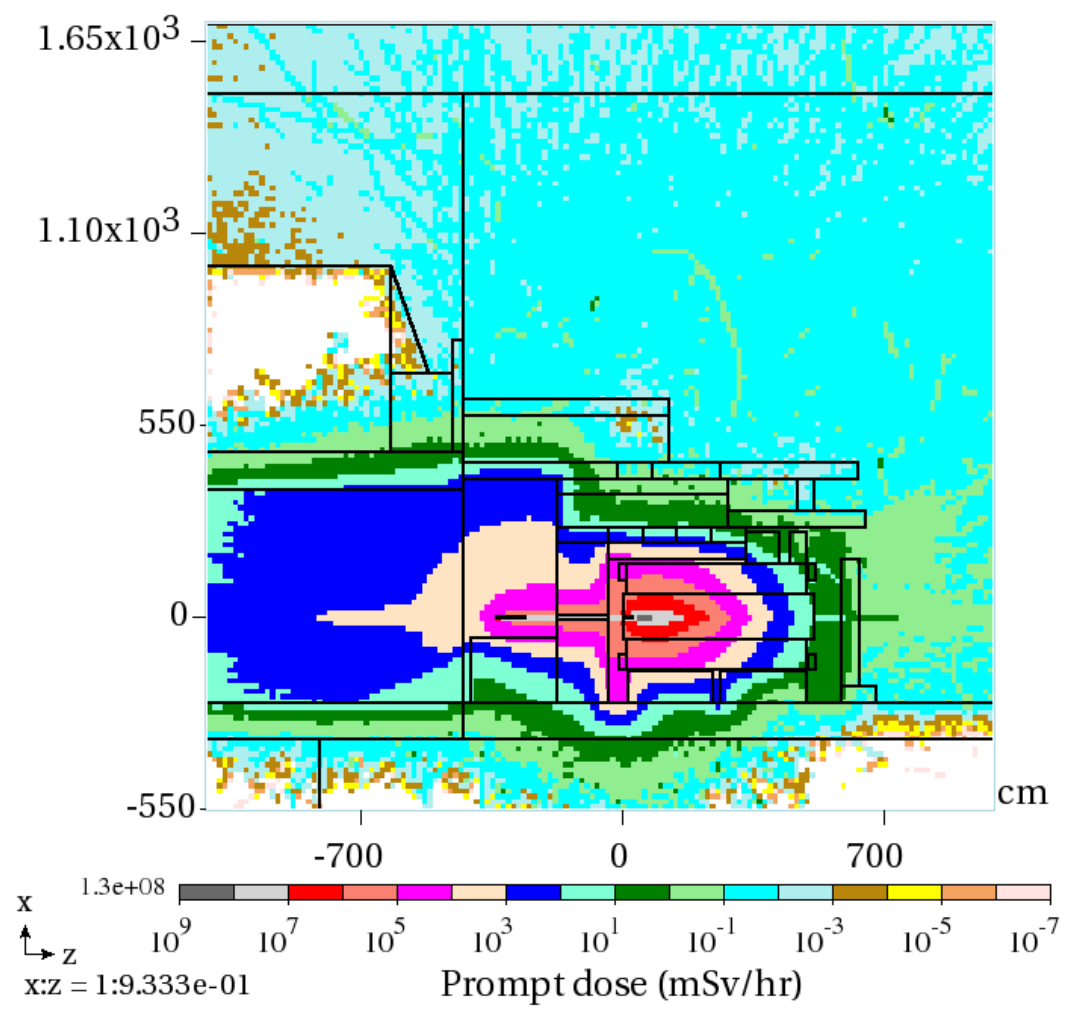

Figure 5. The calculated prompt dose distributions around NM4. 

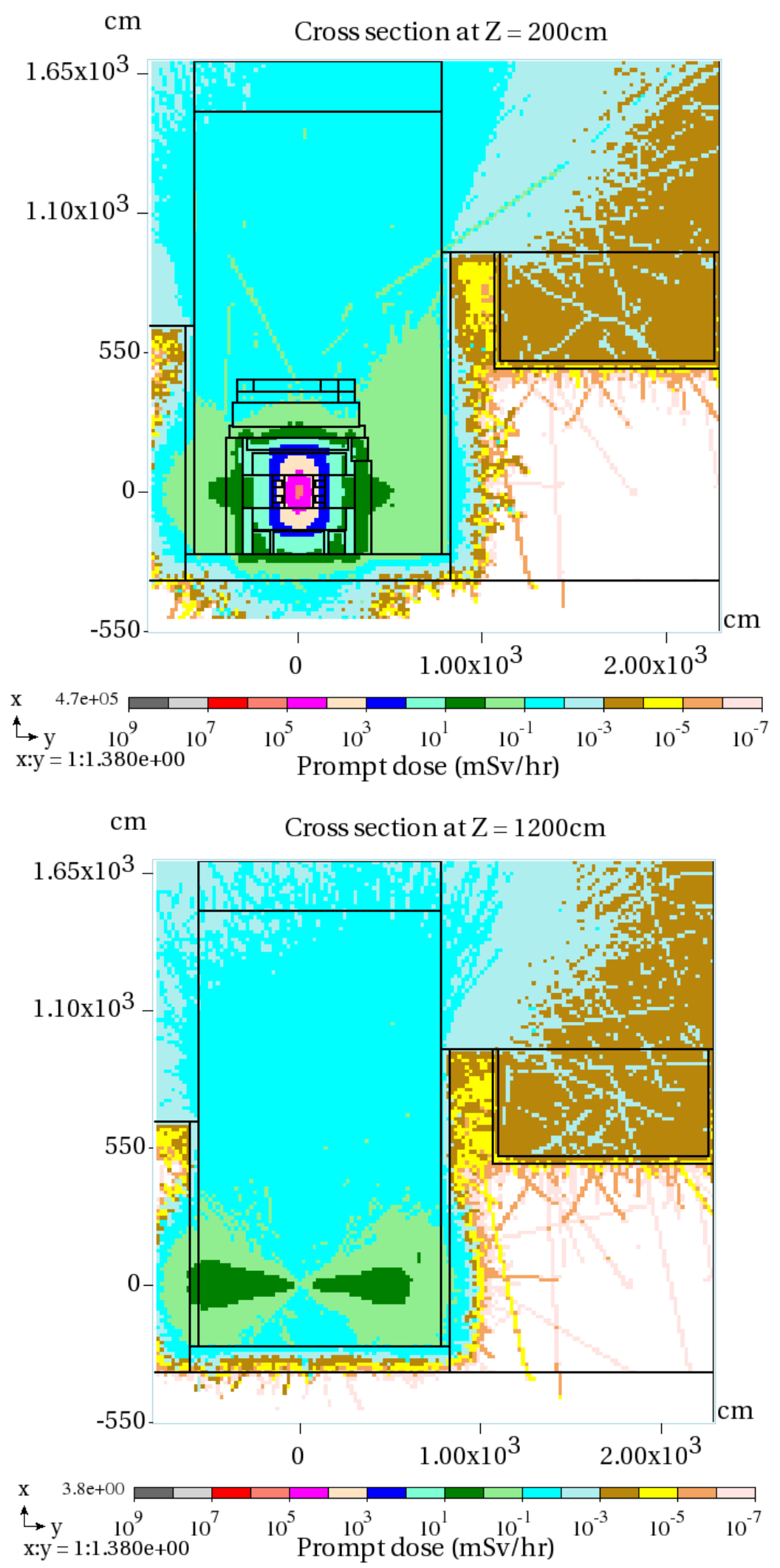

Figure 6. The calculated prompt dose distributions in the counting room at two different longitudinal locations. 

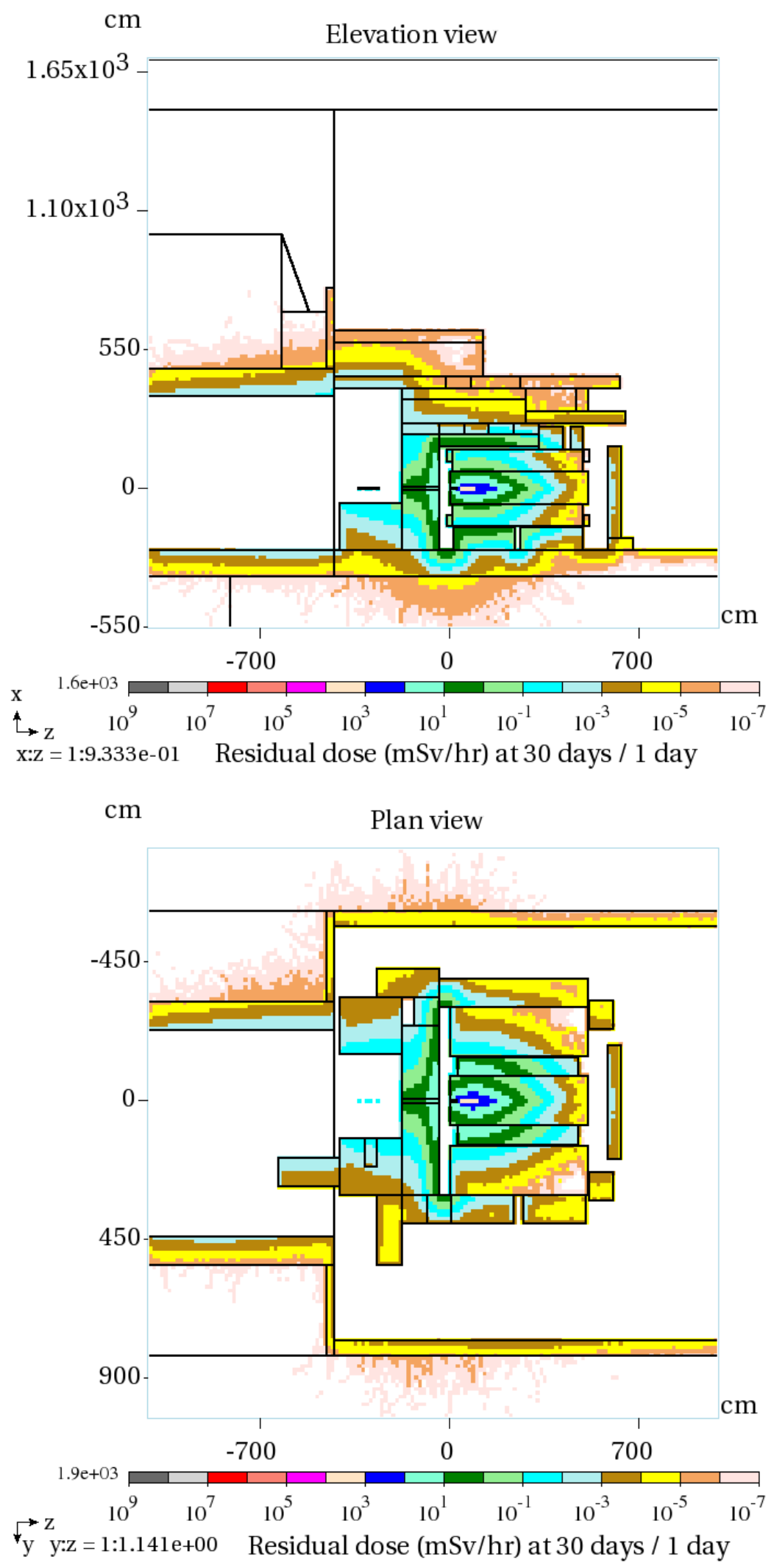

Figure 7. The calculated residual dose distributions (30-day irradiation followed by a 1-day cooling) around the magnet. 

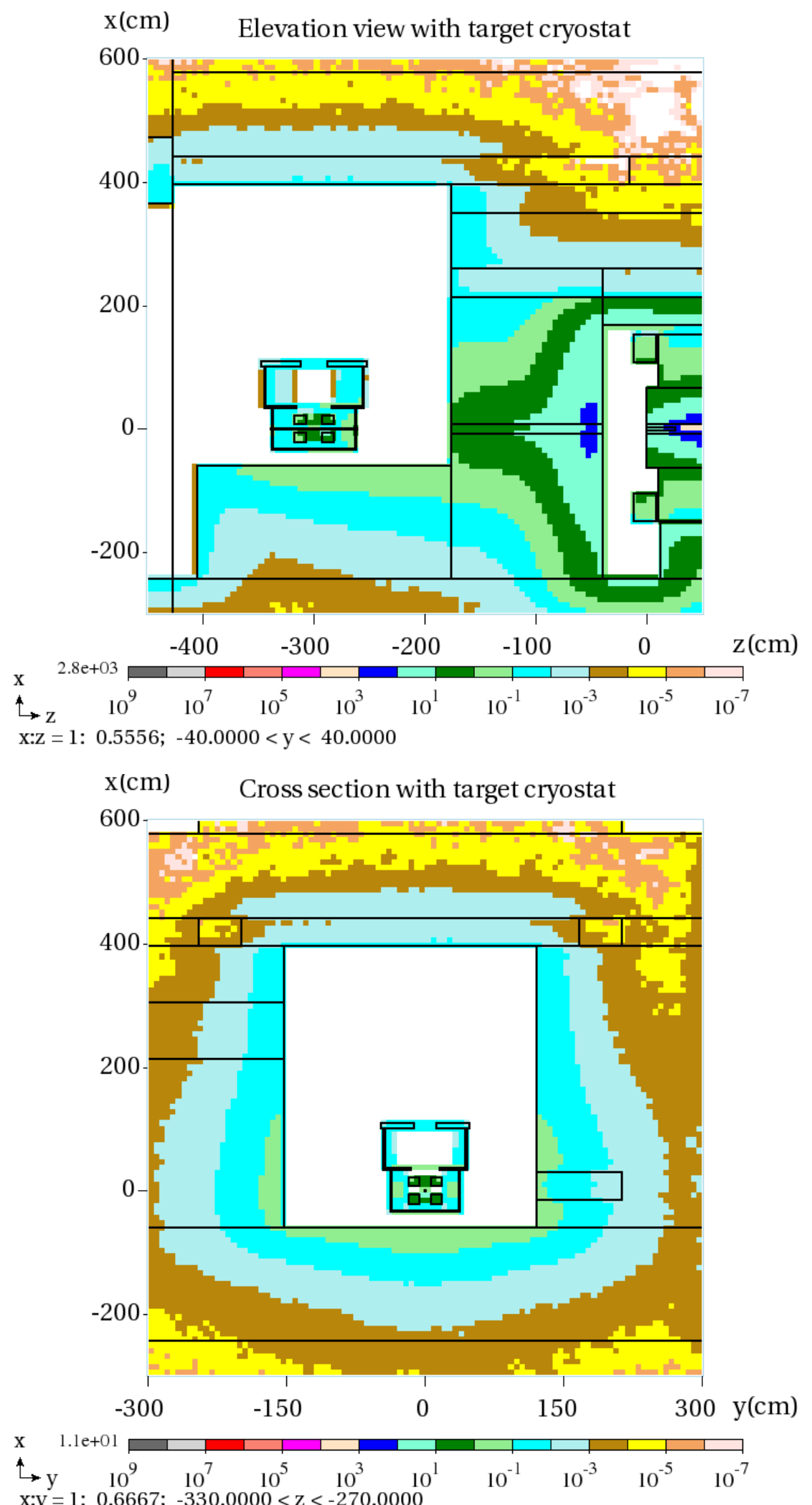

Figure 8 . The calculated residual dose $(\mathrm{mSv} / \mathrm{hr}$ ) distributions (6-month irradiation followed by a 3-hour cooling) around the target alcove with target cryostat. 
Table 1. Contact residual dose (mSv/hr) after a 6-month irradiation.

\begin{tabular}{|c|c|c|c|c|c|}
\hline Item & \multicolumn{5}{|c|}{ Cooling time (hr) } \\
\hline $\begin{array}{c}\text { Cryostat steel } \\
\text { case* }\end{array}$ & 0.53 & 0.50 & 0.47 & 0.43 & 0.40 \\
\hline $\begin{array}{c}\text { Copper coils } \\
\text { inside } \\
\text { cryostat }\end{array}$ & 10.0 & 9.2 & 8.7 & 7.8 & 6.6 \\
\hline
\end{tabular}

${ }^{*} \mathrm{~A}$ conservative (overestimated) value.

The above-mentioned points of interest calculated for E906 are given in Table 2 which is reproduced from reference [1]. Columns 3 and 4 in Table 2 show the dose values calculated at these specific locations for the E906 shielding configuration and their liquid deuterium target. In the Figures 9 thru 11 below, comparisons are shown between the shielding calculations for E906 and E1039 at these same locations and summarized in Table 3. One can see that dose values at these locations for E1039 experiment are lower or do not exceed dose values calculated for E906. Also, from Figure 6 one can see that the prompt dose in the counting room does not exceed the maximum estimation of approximately $2 \times 10^{-3} \mathrm{mSv} / \mathrm{hr}$. The discrepancy with the original lowdose prediction in the counting house for E906 arises from scaling point $\mathrm{C}$ through 8.5' of dirt and neglecting the large contribution of skyshine which is evident from Figure 6. Skyshine was included in the current model giving the larger prompt dose. Given the reduced neutron prompt dose due to increased concrete shielding, the dose in the counting house is anticipated to be significantly less than E906. The optimized shielding configuration for E1039 provides greatly improved radiation protection relative to the E906 shielding configuration.

Table 2. Total prompt dose at points of interest.

\begin{tabular}{|c|c|c|c|c|c|c|}
\hline Point & Location & $\begin{array}{c}\text { Dose Rate } \\
\text { (mSv/hr) }\end{array}$ & $\begin{array}{c}\text { Dose Rate } \\
\text { (mrem/hr) }\end{array}$ & $\begin{array}{c}\text { Dose Rate } \\
\text { after } \\
\text { shielding } \\
\text { additional } \\
\text { shielding } \\
\text { (mrem/hr) }\end{array}$ & $\begin{array}{c}\text { FRCM } \\
\text { (mrem/hr) }\end{array}$ \\
\hline A & $\begin{array}{c}\text { Inside NM4 at upstream } \\
\text { end of concrete cave - } \\
\text { beam left }\end{array}$ & 1 & 100 & 5 feet of dirt & 1.64 & $5 \leq \mathrm{DR} \leq 100$ \\
\hline B & $\begin{array}{c}\text { Inside NM4 looking North } \\
\text { or downstream - Parking lot }\end{array}$ & 1 & 100 & $\begin{array}{c}8.5 \text { feet of } \\
\text { dirt }\end{array}$ & 0.092 & $.05 \leq \mathrm{DR} \leq 0.25$ \\
\hline C & $\begin{array}{c}\text { Inside NM4 adjacent to } \\
\text { NM4 gas shed }\end{array}$ & 0.1 & 10 & $\begin{array}{c}8.5 \text { feet of } \\
\text { dirt }\end{array}$ & 0.0092 & $.05 \leq \mathrm{DR} \leq 0.25$ \\
\hline $\mathrm{D}$ & $\begin{array}{c}\text { Inside NM4 roof above the } \\
\text { upstream end of the } \\
\text { concrete cave }\end{array}$ & 0.1 & 10 & N/A & 10 & $5 \leq \mathrm{DR} \leq 100$ \\
\hline
\end{tabular}


Table 3. Comparison of

\begin{tabular}{|c|c|c|c|c|c|c|}
\hline Point & Location & $\begin{array}{l}\text { Dose Rate } \\
\text { (mSv/hr) }\end{array}$ & $\begin{array}{l}\text { Dose Rate } \\
\text { (mrem/hr) }\end{array}$ & $\begin{array}{l}\text { Additional } \\
\text { Shielding }\end{array}$ & $\begin{array}{l}\text { Dose Rate } \\
\text { scaled for } \\
\text { additional } \\
\text { shielding } \\
\text { (mrem/hr) }\end{array}$ & $\begin{array}{c}\text { FRCM } \\
\text { (mrem/hr) }\end{array}$ \\
\hline $\begin{array}{c}\text { A } \\
\text { E906 } \\
\text { E1039 } \\
\end{array}$ & $\begin{array}{l}\text { Inside NM4 at } \\
\text { upstream side of } \\
\text { concrete cave }\end{array}$ & $\begin{array}{c}1 \\
0.3\end{array}$ & $\begin{array}{c}100 \\
30\end{array}$ & $\begin{array}{l}5 \text { ' of dirt } \\
\text { same }\end{array}$ & $\begin{array}{l}1.64 * \\
0.49 *\end{array}$ & $\begin{array}{c}5 \leq \mathrm{DR} \leq 100 \\
\mathrm{DR} \leq 1\end{array}$ \\
\hline $\begin{array}{c}\text { B } \\
\text { E906 } \\
\text { E1039 }\end{array}$ & $\begin{array}{l}\text { Inside NM4 looking } \\
\text { north or downstream } \\
\text { towards parking lot }\end{array}$ & $\begin{array}{c}1 \\
0.3\end{array}$ & $\begin{array}{c}100 \\
30\end{array}$ & $\begin{array}{l}\text { 8.5' of dirt } \\
\text { same }\end{array}$ & $\begin{array}{l}0.092^{*} \\
0.028 *\end{array}$ & $0.05 \leq \mathrm{DR} \leq 0.25$ \\
\hline $\begin{array}{c}\text { C } \\
\text { E906 } \\
\text { E1039 }\end{array}$ & $\begin{array}{l}\text { Inside NM4 adjacent } \\
\text { to gas shed, ( } z=475, \\
\text { E906) }\end{array}$ & $\begin{array}{l}0.1 \\
0.1\end{array}$ & $\begin{array}{l}10 \\
10\end{array}$ & $\begin{array}{l}8.5^{\prime} \text { of dirt } \\
\text { included }\end{array}$ & $\begin{array}{c}0.0092 * \\
0.2\end{array}$ & $0.05 \leq \mathrm{DR} \leq 0.25$ \\
\hline D & $\begin{array}{l}\text { Just below NM4 roof } \\
\text { at upstream end of } \\
\text { concrete cave }\end{array}$ & $\begin{array}{c}0.1 \\
0.01 \\
\end{array}$ & $\begin{array}{c}10 \\
1 \\
\end{array}$ & N/A & $\begin{array}{c}10 \\
1 \\
\end{array}$ & $\begin{array}{c}5 \leq \mathrm{DR} \leq 100 \\
1 \leq \mathrm{DR} \leq 5\end{array}$ \\
\hline E1039 & $\begin{array}{l}\text { Counting house } \\
\text { upstream, } z=200\end{array}$ & 0.002 & 0.2 & $\begin{array}{l}\text { includes } \\
8.5^{\prime} \text { of dirt }\end{array}$ & 0.2 & $0.05 \leq \mathrm{DR} \leq 0.25$ \\
\hline E1039 & $\begin{array}{c}\text { Counting house } \\
\text { downstream, } z=1200\end{array}$ & 0.002 & 0.2 & $\begin{array}{l}\text { includes } \\
8.5^{\prime} \text { of dirt }\end{array}$ & 0.2 & $0.05 \leq \mathrm{DR} \leq 0.25$ \\
\hline
\end{tabular}

*does not include skyshine which is the dominant contribution to prompt dose 

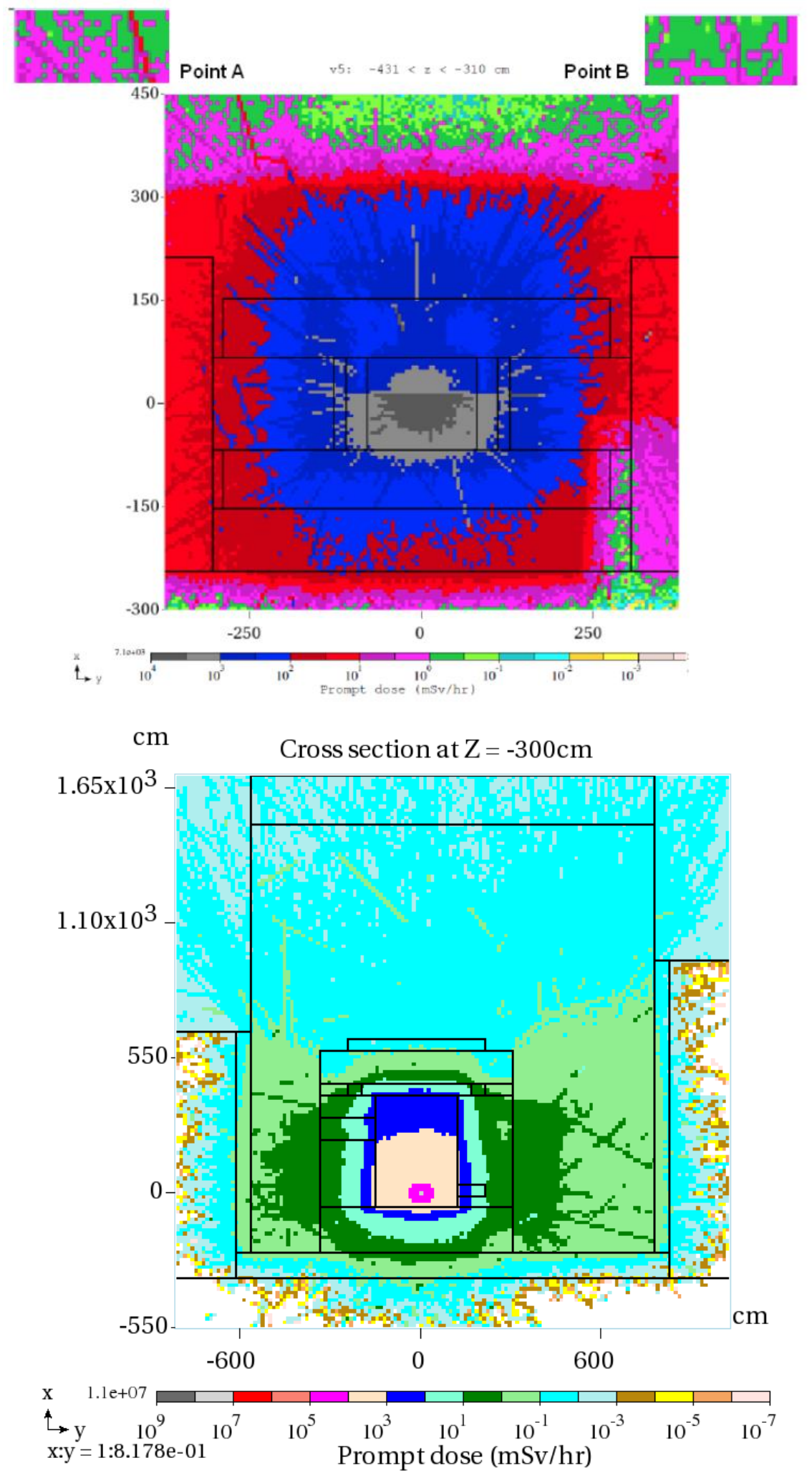

Figure 9. The calculated residual dose (mSv/hr) distributions for E906 (top) and E1039 (bottom). The dose at points A and B are approximately equal to 1 and $0.3 \mathrm{mSv} / \mathrm{hr}$ for E906 and E1039, respectively. 


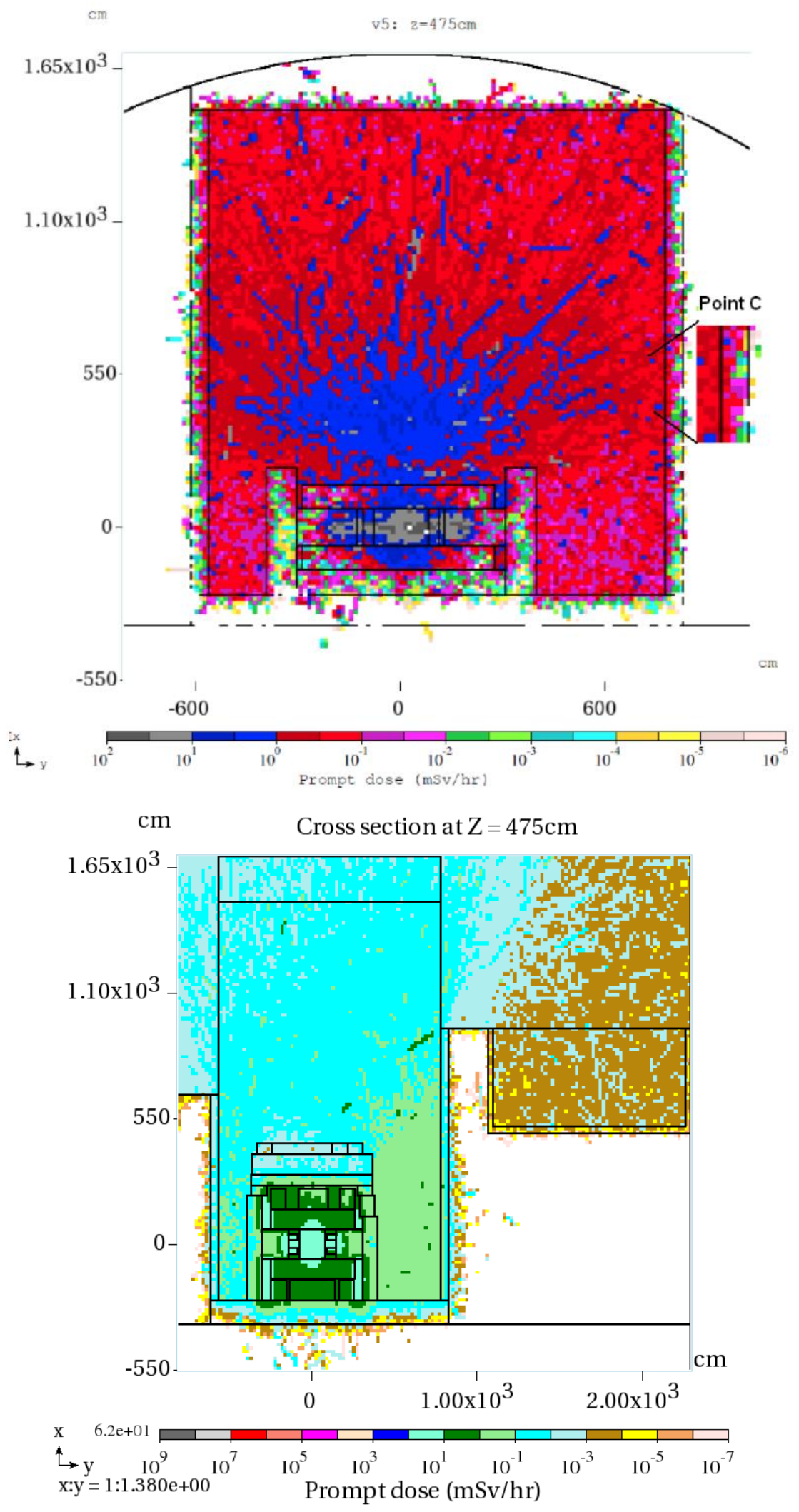

Figure 10. The calculated prompt dose (mSv/hr) distributions for E906 (top) and E1039 (bottom). The dose at point $\mathrm{C}$ is approximately equal to $0.1 \mathrm{mSv} / \mathrm{hr}$ for both $\mathrm{E} 906$ and E1039. 

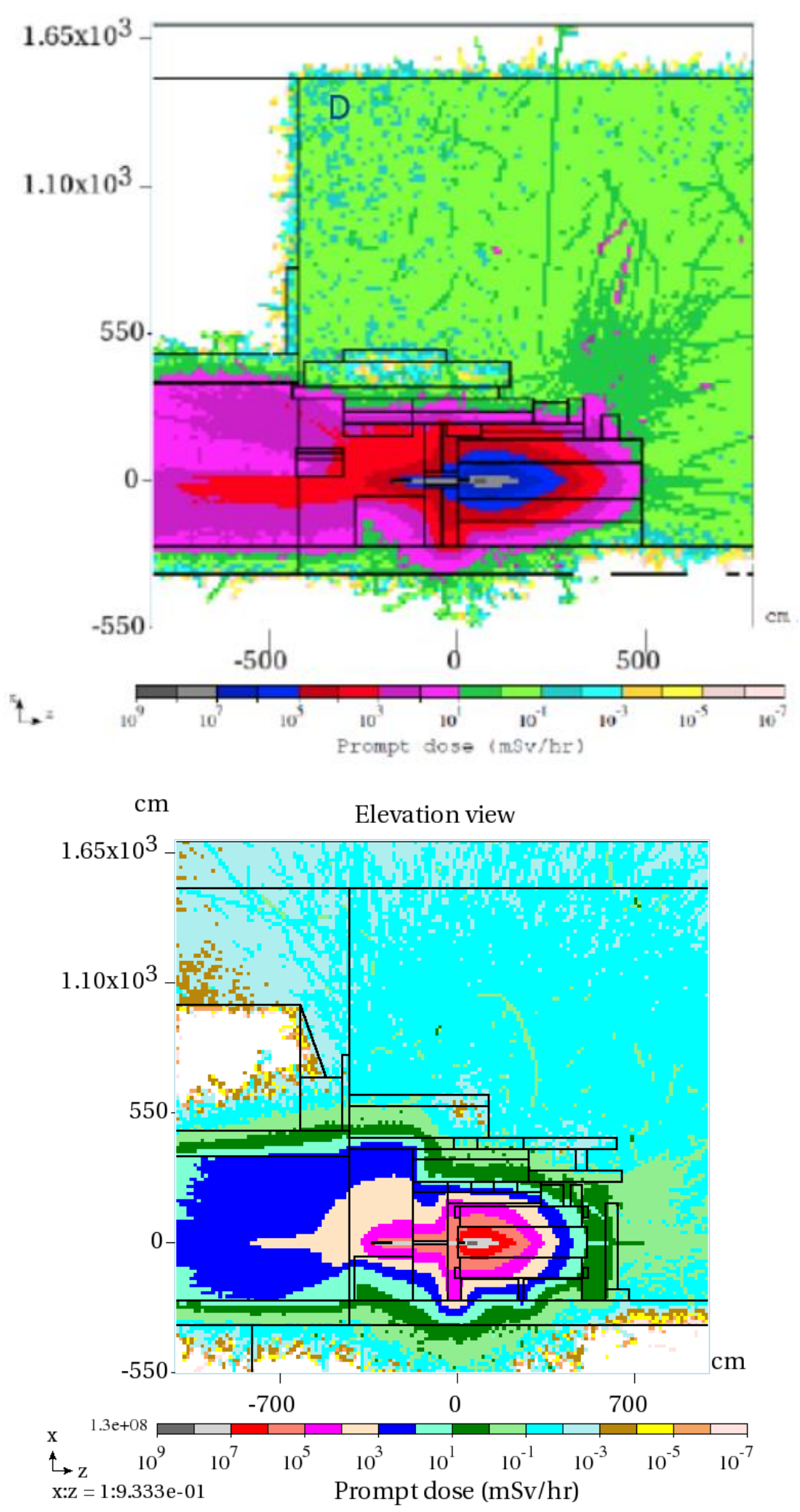

Figure 11. The calculated residual prompt (mSv/hr) distributions for E906 (top) and E1039 (bottom). The dose at point $\mathrm{D}$ is approximately equal to 0.1 and $0.01 \mathrm{mSv} / \mathrm{hr}$ for E906 and E1039, respectively. 
In summary, E1039 prompt dose reductions vary from about a factor of 2 to as high as 10 . Further the skyshine and neutron prompt dose are thermal which allows for either borated poly or poly sheets to be effective locally if required for shielding occupied areas or sensitive equipment.

\section{References}

[1] D. Christian, M. Geelhoed, N. Mokhov, E906-SeaQuest MARS15 simulation, Fermilab-TM-2479-AD-E, 2011.

[2] N. V. Mokhov, The MARS Code System User's Guide, Fermilab-FN-628 (1995);

N. V. Mokhov et al., Prog. Nucl. Sci. Technol. 4, 496 (2014); https://mars.fnal.gov 